\title{
Short-term and intermediate-term readmission after esophagectomy
}

\author{
Yoyo Wang ${ }^{1 \#}$, Chi-Fu Jeffrey Yang ${ }^{2 \#}$, Hao He ${ }^{3}$, Josephine M. Buchan ${ }^{4}$, Deven C. Patel ${ }^{3}$, Douglas Z. Liou ${ }^{3}$, \\ Natalie S. Lui ${ }^{3}$, Mark F. Berry ${ }^{3,5}$, Joseph B. Shrager ${ }^{3,5}$, Leah M. Backhus, \\ ${ }^{1}$ University of Michigan Medical School, Ann Arbor, MI, USA; ${ }^{2}$ Department of Surgery, Division of Thoracic Surgery, Massachusetts General \\ Hospital, Boston, MA, USA; ${ }^{3}$ Division of Thoracic Surgery, Department of Cardiothoracic Surgery, Stanford University Medical Center, Falk \\ Building, Stanford, CA, USA; ${ }^{4}$ University of California, Berkeley, Berkeley, CA, USA; ${ }^{5}$ Department of Cardiothoracic Surgery, Division of Thoracic \\ Surgery, VA Palo Alto Health Care System, Palo Alto, CA, USA \\ Contributions: (I) Conception and design: LM Backhus, CFJ Yang, Y Wang, H He; (II) Administrative support: DZ Liou, NS Lui, MF Berry, JB \\ Shrager, LM Backhus; (III) Provision of study materials or patients: DZ Liou, NS Lui, MF Berry, JB Shrager, LM Backhus; (IV) Collection and \\ assembly of data: H He, CFJ Yang, Y Wang, DC Patel; (V) Data analysis and interpretation: Y Wang, CFJ Yang, H He, JM Buchan; (VI) Manuscript \\ writing: All authors; (VII) Final approval of manuscript: All authors. \\ \#These authors contributed equally to this work. \\ Correspondence to: Leah M. Backhus. 300 Pasteur Dr., Stanford, CA 94305, USA. Email: lbackhus@stanford.edu.
}

Background: The objective of this study was to characterize short- and intermediate-term readmissions following esophagectomy and to identify predictors of readmission in these two groups.

Methods: Patients who underwent esophagectomy in the National Readmissions Database (20132014) were grouped according to whether first readmission was "short-term" (readmitted $<30$ days) or "intermediate-term" (readmitted 31-90 days) following index admission for esophagectomy. Predictors of readmission were evaluated using multivariable logistic regression modeling.

Results: Of the 3,005 patients who underwent esophagectomy, 544 (18.1\%) had a short-term readmission and $305(10.1 \%)$ had an intermediate-term readmission. The most frequent reasons for short-term readmission were post-operative infection $(7.5 \%)$, dysphagia $(6.3 \%)$ and pneumonia $(5.1 \%)$. The most common intermediate-term complications were pneumonia (7.2\%), gastrointestinal stricture/stenosis $(6.9 \%)$ and dysphagia (5.9\%). In multivariable analysis, being located in a micropolitan area, increasing number of comorbidities and higher severity of illness score were associated with an increased likelihood of having a short-term readmission while being discharged to a facility (as opposed to directly home) was associated with increased likelihood of both short- and intermediate-term readmission (all $\mathrm{P}<0.05$ ).

Conclusions: In this analysis, postoperative infection was the most common reason for short-term readmission. Dysphagia and pneumonia were common reasons for both short- and intermediate-term readmission of patients following esophagectomy. Interventions focused on reducing the risk of postoperative infection and pneumonia may reduce hospital readmissions. Gastrointestinal stricture and dysphagia were associated with increased risk of intermediate readmission and should be examined in the context of morbidity associated with pyloric procedures (e.g., pyloromyotomy) at the time of esophagectomy.

Keywords: Esophageal cancer; esophagectomy; readmission; short-term; intermediate-term

Submitted Apr 13, 2021. Accepted for publication Jun 25, 2021.

doi: $10.21037 /$ jtd-21-637

View this article at: https://dx.doi.org/10.21037/jtd-21-637

(c) Journal of Thoracic Disease. All rights reserved. 


\section{Introduction}

In the United States, hospital readmission has become an important metric for healthcare quality (1) and has garnered the attention of national policy makers, particularly because readmissions are associated with poor outcomes and high costs (2). Of note, the Healthcare Readmissions Reduction Program (HRRP) has created financial incentives, such as penalties, for hospitals to reduce the rate of readmission within 30 days (1). Readmissions following esophagectomy are not infrequent-data from the past decade have found the 30 -day readmissions rates range from approximately $6 \%$ to $11 \%$ (3-5) - and are associated with worse 90-day mortality (6) and long-term survival (7). However, to date, the frequency, type and predictors of readmissions following esophagectomy are not well characterized. Studies of short-term readmission are largely limited to older data and, to our knowledge, there are no national studies reporting detailed data on characteristics and predictors of intermediate-term readmissions (readmissions 31-90 days following esophageal resection).

In the present study, we analyzed two years of data in the National Readmissions Database (2013 and 2014) of patients who underwent esophagectomy. The objective was to characterize short-term (0-30 days after index admission for esophagectomy) and intermediate-term (31-90 days after index admission for esophagectomy) readmissions following esophagectomy and to identify predictors of readmission in these two groups.

We present the following article in accordance with the STROBE reporting checklist (available at https://dx.doi. org/10.21037/jtd-21-637).

\section{Methods}

\section{National Readmissions Database}

The National Readmission Database (NRD) is one of the databases developed by the Healthcare Cost and Utilization Project (HCUP) to track patient discharge and subsequent readmissions (8). The data from the NRD is derived from the State Independent Databases (SID) and includes the discharge data from 27 states (8). The data in the NRD accounts for approximately $57.8 \%$ of the U.S. population and $56.6 \%$ of all hospitalizations in the U.S. Procedural and diagnostic codes related to esophagectomy were recorded in the NRD using the International Classification of Diseases (ICD) $9^{\text {th }}$ edition for the years of study inclusion (8). The study was conducted in accordance with the Declaration of Helsinki (as revised in 2013). This retrospective study was approved by the Stanford
University Institutional Review Board (IRB \# 35143) and individual consent for this retrospective analysis was waived.

\section{Study design}

All patients who received an esophagectomy in the NRD from January $1^{\text {st }} 2013$ to September $30^{\text {th }} 2013$ and January $1^{\text {st }} 2014$ to September $30^{\text {th }} 2014$ were identified for inclusion. We used the ICD-9 procedural codes that were used in previous studies to define the esophagectomy cohorts $(7,9)$. Additionally, we only focused on data from 2013 to 2014 in the National Readmissions Database as these were the last years that the NRD used ICD-9 coding. Patients were excluded if they had emergent surgery, died during the initial hospitalization, or if their operation was coded as being a same-day procedure. Currently, there is no outpatient esophageal resection procedure, so we excluded these patients to improve the accuracy of our analysis. Additionally, patients with any history of cancer were also excluded from this study due to the frailty of cancer survivors and the lack of information about the type of cancer the patient previously had. For certain variables a category of other/unknown was created for patients with missing data.

\section{Statistical analysis}

We evaluated the cohort of patients who received esophagectomy and stratified them into three subgroups: (I) patients who were not readmitted within 90 days, (II) patients who were readmitted in the short-term (0-30 days after discharge), and (III) patients who were readmitted in the intermediate-term (31-90 days after discharge). Comparisons of baseline characteristics and unadjusted outcomes were performed using the Kruskal-Wallis or one-way ANOVA tests for continuous variables and Pearson's chi-square and Fisher's exact test for discrete variables. Predictors of short-term and intermediate-term readmission were evaluated using multivariable logistic regression modeling that included variables felt to be relevant to readmission. These variables included: age, sex, median household income, insurance type, patient location, residency of state, length of stay, co-morbidity score (which was created by adding up the number of comorbidities listed for each patient), the All Patient Refined-Diagnosis Related Group (APR-DRG) risk of mortality (ROM) score, the APR-DRG severity of illness score, disposition of patients, use of rehab facility, as well as, the ownership, size, 
teaching status, and location of the hospital. Complications were determined using the "DXn" element in the NRD (8).

For all comparisons, a $\mathrm{P}$ value of 0.05 was used to define statistical significance. Statistical analysis was performed using Stata/MP software, version 13.1 for Mac (StataCorp, College Station, TX, USA).

\section{Results}

\section{Patient demographics}

Of the 3,005 patients who underwent an esophagectomy and met our inclusion criteria (Figure S1), 544 (18.1\%) patients were readmitted within 30 days, 305 (10.1\%) patients were readmitted within 31-90 days, and 2,156 $(71.8 \%)$ patients were not readmitted within 90 days. Baseline characteristics are detailed in Tables 1 and 2. The different types of anastomotic techniques are detailed in Table S1. The short- and intermediate-term readmission groups had one additional comorbidity when compared to patients who were not readmitted within 90 days. There was also a higher percentage of patients with Medicare in the short- and intermediate-term readmission group when compared to patients that were not readmitted within 90 days. There was a higher percentage of patients in the short-term and intermediate-term readmission groups that had alcohol abuse, chronic pulmonary disease, coagulopathy, diabetes, hypertension, hypothyroidism, fluid and electrolyte disorder, neurological disorder, peripheral vascular disease, psychoses, renal failure, and weight loss (Table 2). The short- and intermediate-term readmission groups also had higher (APR-DRG) risk mortality and severity of illness scores when compared to the patients who were not readmitted within 90 days.

The majority of the cohort underwent an esophagectomy at a large, private (not-for-profit), metropolitan teaching hospital located in a large metropolitan area (Table 1). When compared to patients who were not readmitted within 90 days, there was a higher percentage of patients in the short- and intermediate-term readmissions group that were discharged first to a short-term hospital, skilled nursing facility, or intermediate care facility prior to being discharged home. The length of hospital stay was shorter for patients who were not readmitted within 90 days (Table 3). The majority of patients in our cohort were not transferred to different hospitals and did not require rehospitalization on the same day (Table 3). Most shortand intermediate-term readmissions were elective. The anastomotic techniques used are highlighted in Table S1.

\section{Short-term readmission}

The three most common broad categories of complications resulting in short-term readmission were: gastrointestinal (28\%), pulmonary (18\%) and infectious (14.5\%) (Table 4). In terms of specific, individual complications that were coded as the primary reason the patient was readmitted between 0-30 days following esophagectomy, the most common complications were post-operative infection (7.5\%), dysphagia $(6.3 \%)$, pneumonia $(5.1 \%)$, bleeding (4.5\%), dehydration (3.7\%), aspiration pneumonitis $(3.3 \%)$, and pain $(2.9 \%)$. The ICD-9 diagnosis code used to define post-operative infection are detailed in Table S2.

\section{Intermediate-term readmission}

The three most common broad categories of complications resulting in intermediate-term readmission were: gastrointestinal $(34 \%)$, pulmonary $(13 \%)$ and infectious $(8.5 \%)$ (Table 4$)$. In terms of specific, individual complications that were coded as the primary reason the patient was readmitted between 31-90 days following esophagectomy, the most common complications were pneumonia $(7.2 \%)$, gastrointestinal stricture/stenosis (6.9\%), dysphagia (5.9\%), and gastrointestinal obstruction (3.3\%).

In a multivariable logistic regression model evaluating predictors of short-term readmission (Table 5), being from a micropolitan area, increasing number of comorbidities, higher APR-DRG severity score, and being discharged to a facility as opposed to directly to home was associated with an increased likelihood of having a short-term readmission. In a multivariable model evaluating predictors of intermediate-term readmission, being discharged to a facility or being discharged with home health care was associated with increased likelihood of having an intermediate-term readmission. Patients that received their esophagectomy at a private hospital were less likely to have an intermediate-term readmission.

\section{Discussion}

In this analysis of readmission patterns for patients who underwent esophagectomy, $18.1 \%$ of patients were readmitted in the short-term (less than 30 days) and $10.1 \%$ of patients were readmitted in the intermediate-term 
Table 1 Baseline patient characteristics

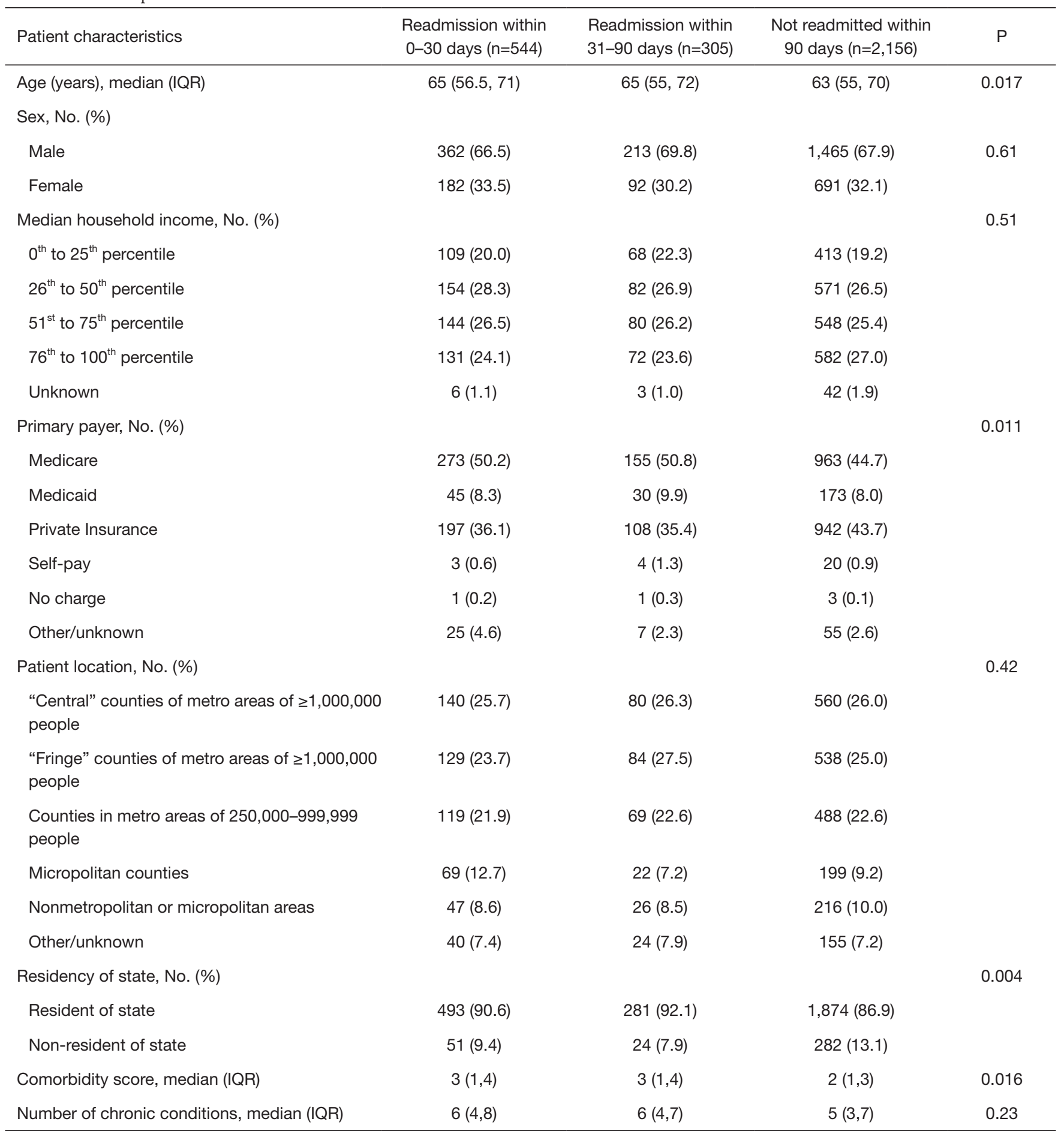

Table 1 (continued) 
Table 1 (continued)

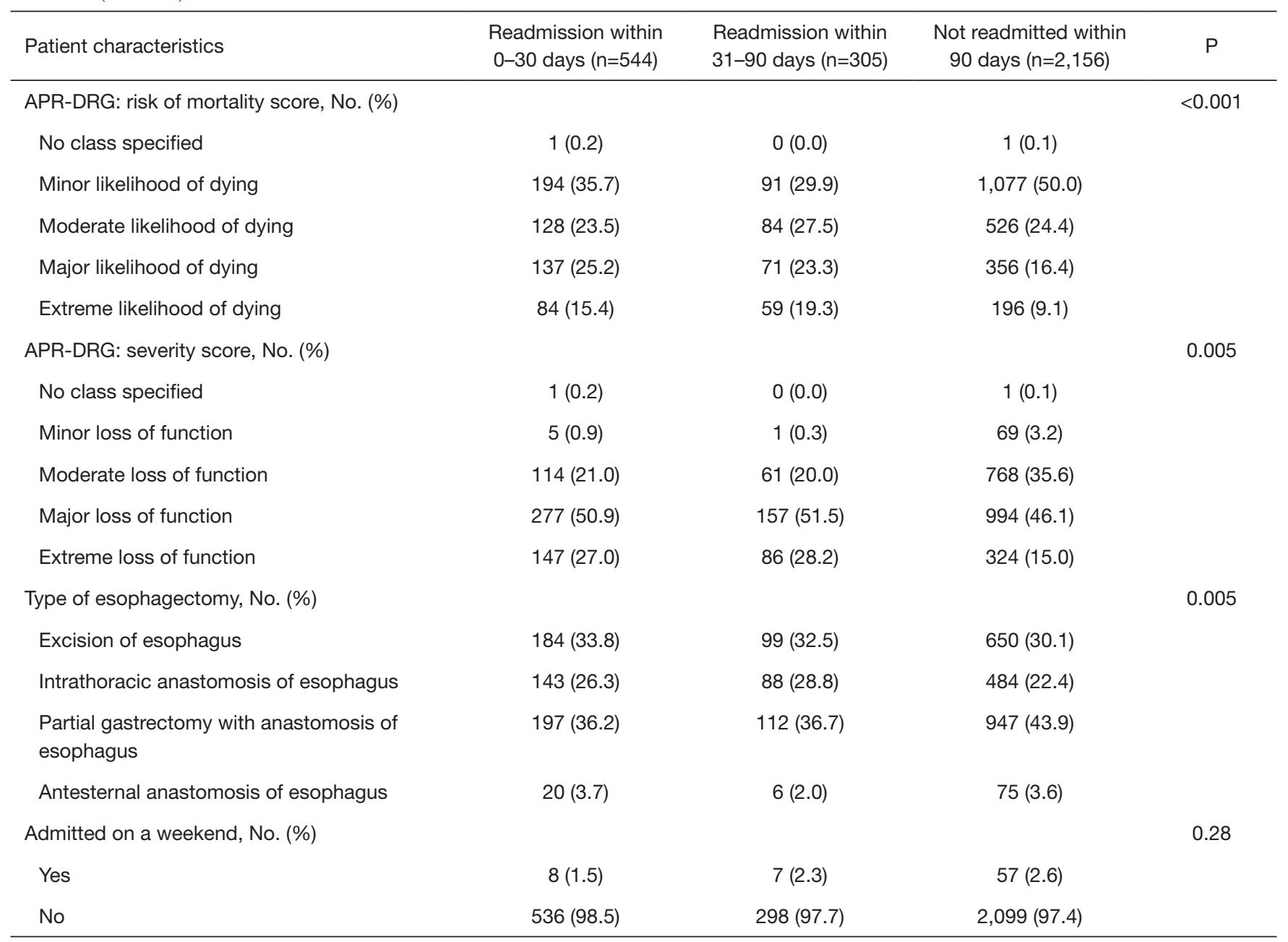

IQR, interquartile range; APR-DRG, all patients refined-diagnosis related groups.

(31-90 days). The most frequent reasons for readmission were post-operative infection (7.5\%), dysphagia (6.3\%) and pneumonia $(5.1 \%)$ for short-term time intervals. The most common intermediate-term complications were pneumonia $(7.2 \%)$, gastrointestinal stricture/stenosis $(6.9 \%)$ and dysphagia (5.9\%). In multivariable analysis, being located in a micropolitan area, increasing number of comorbidities and higher severity of illness score were associated with an increased likelihood of having a short-term readmission while being discharged to a facility (as opposed to directly home) was associated with increased likelihood of both short- and intermediate-term readmission.

The short-term readmission rate of $18.1 \%$ in the present study is consistent with the rates of $6 \%$ to $21 \%$ reported in prior single- and multi-institutional studies and older national analyses $(6,7,9-17)$, although it is slightly higher than that noted by the most recent national analyses of the American College of Surgeons National Surgical Quality Program and the National Cancer Data Base, which report a 30 -day readmission rate of $6 \%$ to $11 \%(3-5)$. However, this discrepancy may be attributed to factors such as differences in surgeon experience, surgical technique, or hospital volume, as surgeon experience has been positively correlated with outcomes after esophagectomy (18).

The intermediate-term readmission rate in this study was $10.1 \%$. To our knowledge, there has been only one other study by Stitzenberg et al. that has reported the rate of readmissions between 31 and 90 days following discharge (7). In that analysis of 1,573 esophagectomies for cancer recorded in the SEER-Medicare database (2001-2007), the 
Table 2 Patient comorbidities

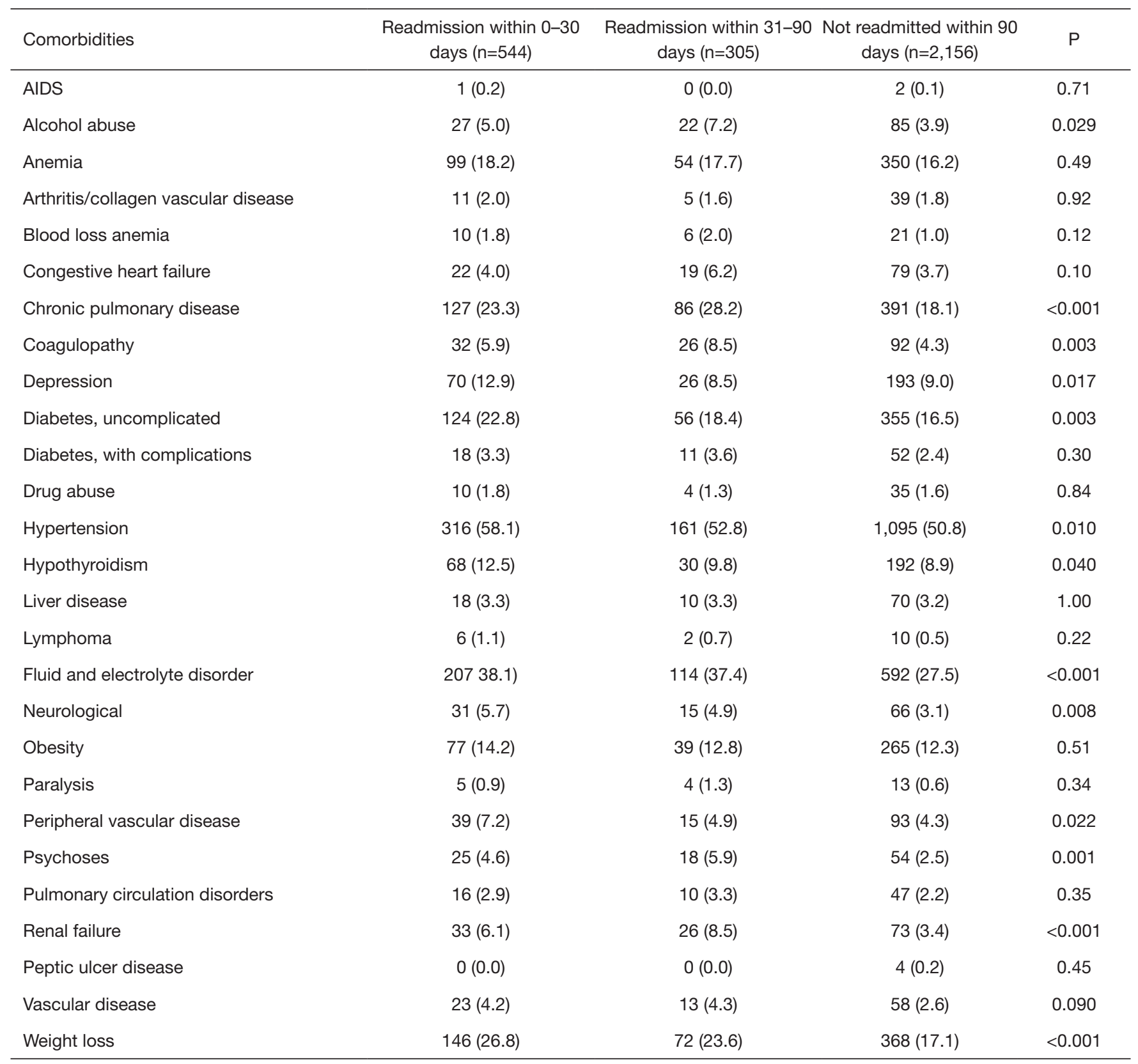

rate of intermediate-term readmission was $12 \%$, which was similar to our findings.

The study findings suggest that strategies to prevent readmissions will probably need to be adjusted throughout the pre- and postoperative period. For example, prevention of postoperative infection will require a multi-pronged approach, and will likely need to start in the preoperative period and include smoking cessation strategies and a plan to improve nutritional status. Common short-term readmissions due to pneumonia, aspiration pneumonitis and dehydration may be prevented, postoperatively, by avoiding oral intake and aspiration and ensuring an adequate hydration plan. To reduce a common cause of intermediateterm readmission such as stricture or gastric outlet obstruction, it is likely important to have close clinical follow up that focuses on swallowing or gastric outlet 
Table 3 Discharge and readmission data

\begin{tabular}{|c|c|c|c|c|}
\hline Discharge disposition & $\begin{array}{l}\text { Readmission within } \\
0-30 \text { days }(n=544)\end{array}$ & $\begin{array}{l}\text { Readmission within } \\
31-90 \text { days }(n=305)\end{array}$ & $\begin{array}{l}\text { Not readmitted within } \\
90 \text { days }(n=2,156)\end{array}$ & $P$ \\
\hline $\begin{array}{l}\text { Disposition of patient at time of initial } \\
\text { admission, No. (\%) }\end{array}$ & & & & $<0.001$ \\
\hline Routine & $175(32.2)$ & $85(27.9)$ & 967 (44.9) & \\
\hline Transfer to short term hospital & $12(2.2)$ & $6(2.0)$ & $17(0.8)$ & \\
\hline Home health care & $232(42.5)$ & $145(47.5)$ & $963(44.6)$ & \\
\hline Against medical advice & $2(0.3)$ & $0(0.0)$ & $1(0.1)$ & \\
\hline Rehab transfer, No. (\%) & & & & 0.029 \\
\hline Initial length of stay, median (IQR) & $11(8,21)$ & $12(8,20)$ & $9(7,13)$ & $<0.001$ \\
\hline Readmission type, No. (\%) & & & & 0.029 \\
\hline Non-elective readmission & $8(1.5)$ & $5(1.6)$ & $12(0.6)$ & \\
\hline Elective readmission & $536(98.5)$ & $300(98.4)$ & $2,144(99.4)$ & \\
\hline
\end{tabular}

$\mathrm{IQR}$, interquartile range.

obstruction issues that could be identified with outpatient management. Other studies have also proposed the use of earlier follow-ups as a means to detect postoperative complications sooner so that complications can be addressed earlier or even treated in the outpatient setting instead of in the hospital (3).

A strength of using the NRD for this study is the ability to include large number of patients from an unbiased population-based database, with volume sufficient to evaluate predictors of readmission. Another strength of this study was the analysis of not only short-term 30-day readmission, which has been previously reported, but also of intermediate-term (31-90 days) readmission. Of note, while there has been one study reporting the 31-90 days readmission rate following esophagectomy (7), this study is the first analysis to characterize complications and identify predictors associated with intermediate-term readmission. Finally, although several studies of readmission following esophagectomy have been performed, they mostly contain data from older time periods in the 2000's $(6,7,9-17)$; our study analyzes data from 2013 and 2014 and may be more representative of current trends and outcomes.

There are several limitations to this study, many of which are related to the limitations of the NRD. First, the NRD does not have information on what the esophagectomy was performed for. Presumably, the majority of esophageal resections in the database was for cancer, but the esophagectomies included in our analysis could have also been for benign disease. Second, there was no information on race, performance status, travel distance, staging, operative time, estimated blood loss, and other important preoperative and intraoperative variables that could impact postoperative outcomes and readmission. Third, there is no information to determine whether the readmission may have been caused by a complication that developed during the index admission. Fourth, there was no information on the extent of follow up care received by the patient after the initial discharge. Fifth, in our cohort, there was no data on several known complications of esophagectomy, such as anastomotic leak, respiratory failure leading to prolonged intubation, and reoperation. Sixth, because there was no data on overall survival, long-term outcomes were not able to be evaluated.

\section{Conclusions}

In this study, post-operative infection was the most common reason for short-term readmission. Dysphagia 
Table 4 Complications associated with esophagectomy at time of short-term and intermediate-term readmission

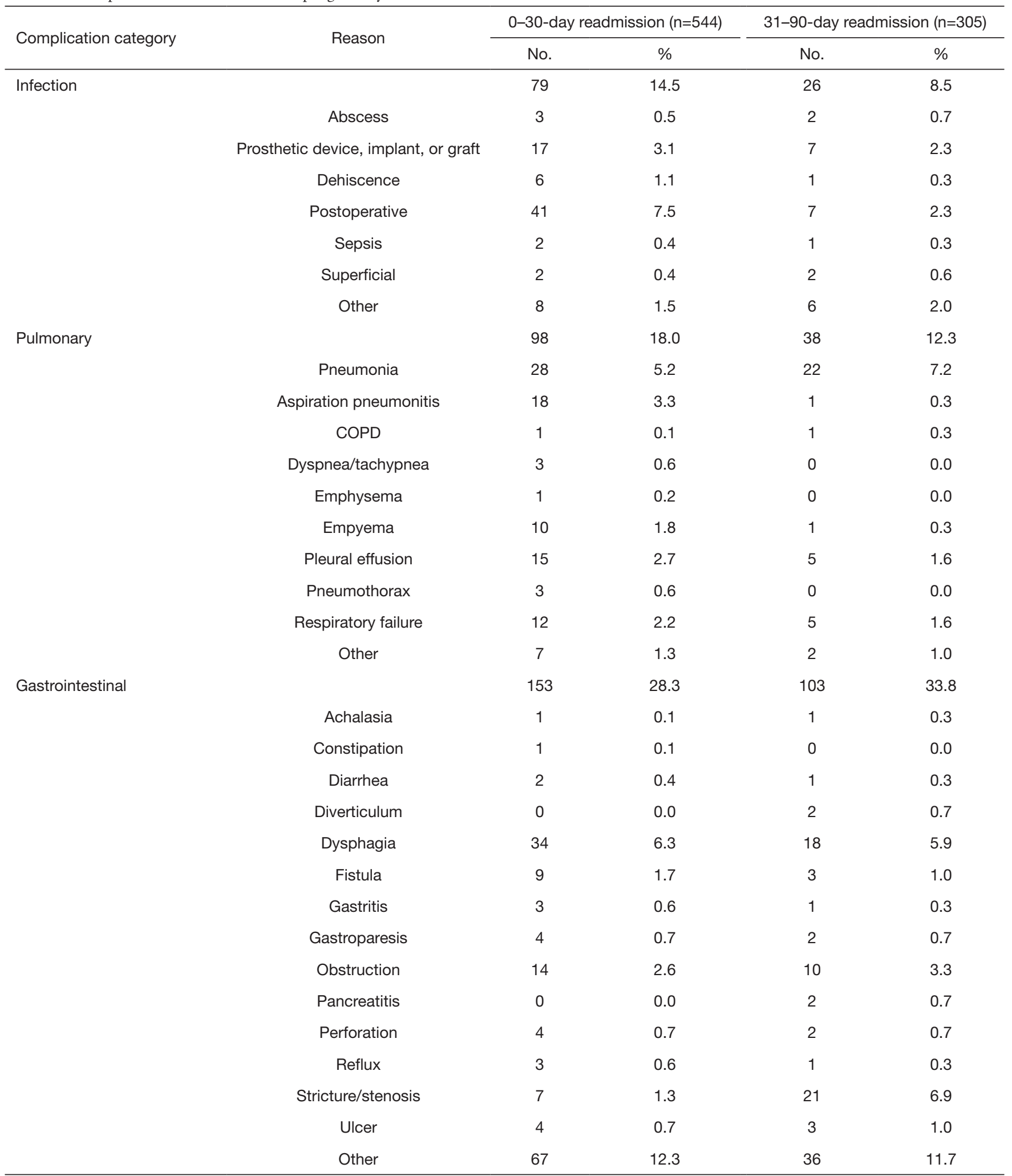

Table 4 (continued) 
Table 4 (continued)

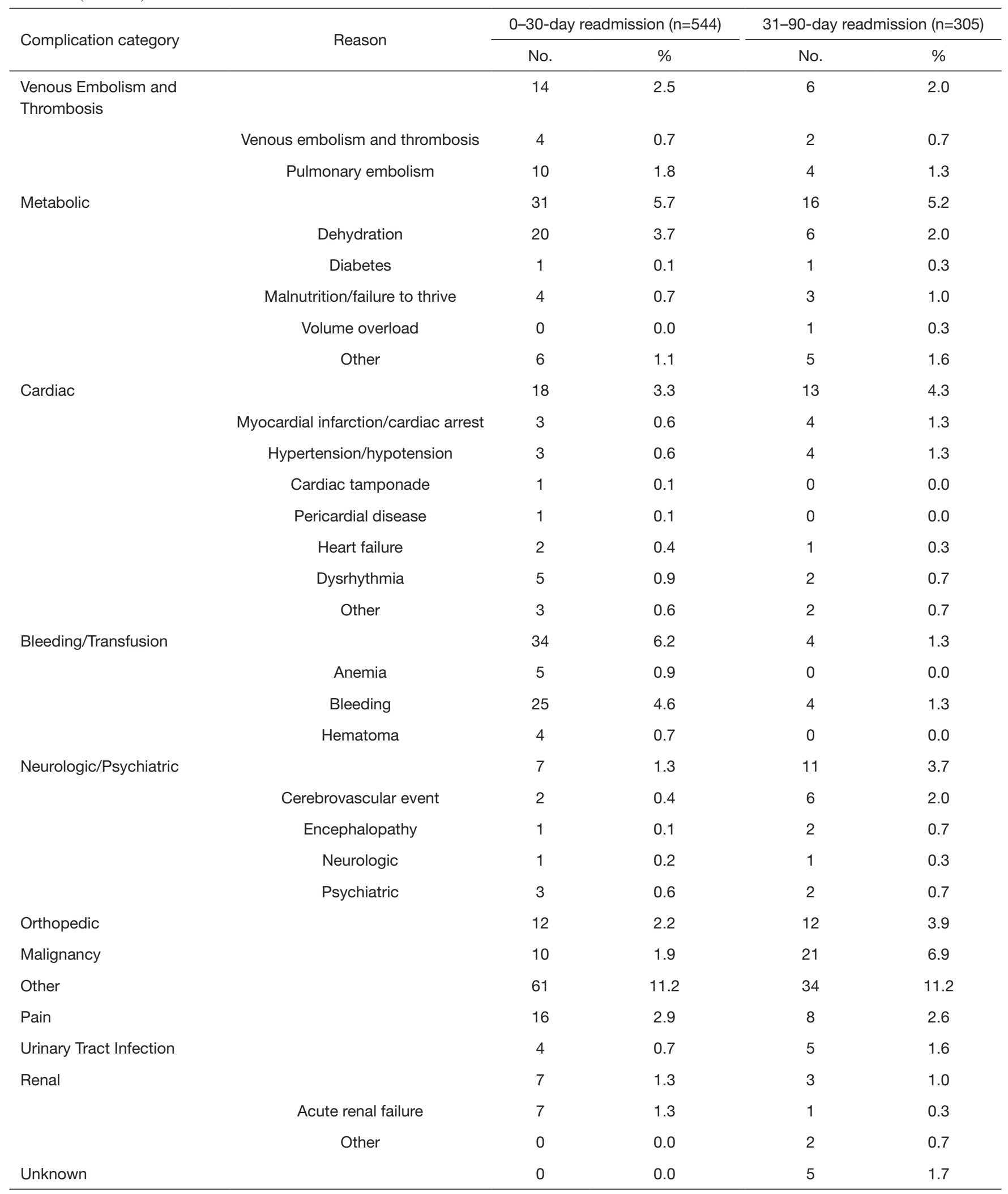


Table 5 Multivariable logistic regression evaluating predictors for readmission 0-30 days following esophagectomy

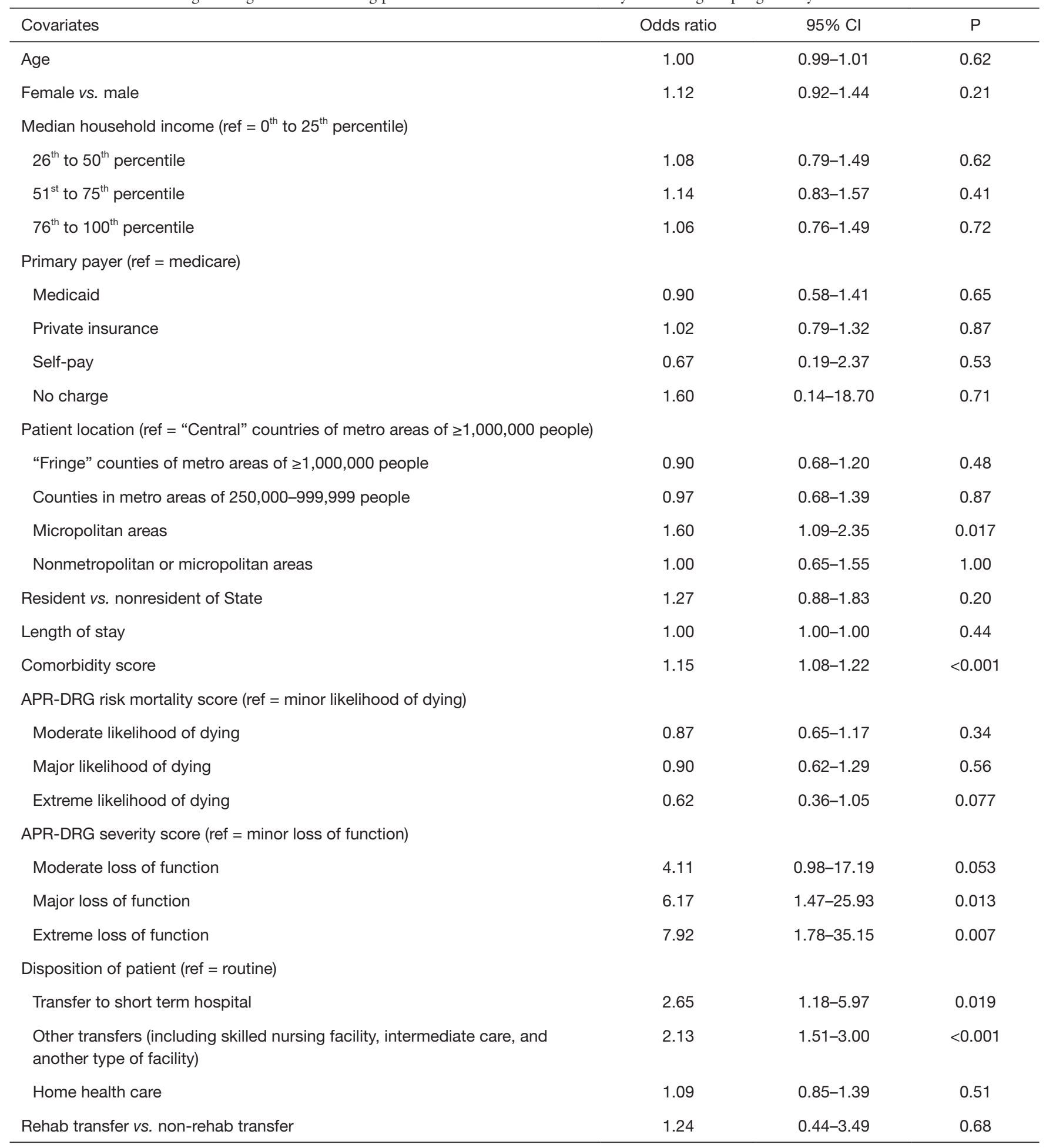

Table 5 (continued) 
Table 5 (continued)

\begin{tabular}{lcc}
\hline Covariates & Odds ratio & $95 \% \mathrm{Cl}$ \\
\hline Control/ownership of hospital (ref = government) & & 0.91 \\
Private, not-for-profit & 0.88 & $0.67-1.24$ \\
Private, investor-owned & & $0.51-1.50$ \\
Size of Hospital (ref = small) & 0.79 & $0.54-1.24$ \\
Medium & 0.95 & $0.65-1.38$ \\
Large & & 0.31 \\
Teaching status of hospital (ref = metropolitan non-teaching) & 0.97 & 0.77 \\
Metropolitan teaching & & $0.69-1.36$ \\
Hospital urban-rural location (ref = large metropolitan areas with at least & & 0.85 \\
1 million residents) & 0.91 \\
Small metropolitan areas with less than 1 million residents & 0.56 \\
\hline
\end{tabular}

APR-DRG, all patients refined-diagnosis related groups.

and pneumonia were common reasons for both shortand intermediate-term readmission of patients following esophagectomy. Interventions focused on reducing the risk of postoperative infection and pneumonia may reduce hospital readmissions. Gastrointestinal stricture and dysphagia were associated with increased risk of intermediate readmission and should be examined in the context of morbidity associated with pyloric procedures at the time of esophagectomy.

\section{Acknowledgments}

Presented at the American College of Surgeons $105^{\text {th }}$ Annual Clinical Congress, Scientific Forum, San Francisco, CA.

Funding: None.

\section{Footnote}

Reporting Checklist: The authors have completed the STROBE reporting checklist. Available at https://dx.doi. org/10.21037/jtd-21-637

Peer Review File: Available at https://dx.doi.org/10.21037/ jtd-21-637

Conflicts of Interest: All authors have completed the ICMJE uniform disclosure form (available at https://dx.doi. org/10.21037/jtd-21-637). Mark F. Berry serves as an unpaid editorial board member of Fournal of Thoracic Disease from Sep 2020 to Aug 2022. Natalie Lui serves as an unpaid editorial board member of Fournal of Thoracic Disease from Sep 2019 to Aug 2021. Chi-Fu Jeffrey Yang serves as an unpaid editorial board member of Fournal of Thoracic Disease from Feb 2021 to Jan 2023. The other authors have no conflicts of interest to declare.

Ethical Statement: The authors are accountable for all aspects of the work in ensuring that questions related to the accuracy or integrity of any part of the work are appropriately investigated and resolved. The study was conducted in accordance with the Declaration of Helsinki (as revised in 2013). This retrospective study was approved by the Stanford University Institutional Review Board (IRB \# 35143) and individual consent for this retrospective analysis was waived.

Open Access Statement: This is an Open Access article distributed in accordance with the Creative Commons Attribution-NonCommercial-NoDerivs 4.0 International License (CC BY-NC-ND 4.0), which permits the noncommercial replication and distribution of the article with the strict proviso that no changes or edits are made and the original work is properly cited (including links to both the formal publication through the relevant DOI and the license). See: https://creativecommons.org/licenses/by-nc-nd/4.0/. 


\section{References}

1. Kassin MT, Owen RM, Perez SD, et al. Risk factors for 30-day hospital readmission among general surgery patients. J Am Coll Surg 2012;215:322-30.

2. Zuckerman RB, Sheingold SH, Orav EJ, et al. Readmissions, Observation, and the Hospital Readmissions Reduction Program. N Engl J Med 2016;374:1543-51.

3. Bhagat R, Bronsert MR, Juarez-Colunga E, et al. Postoperative Complications Drive Unplanned Readmissions After Esophagectomy for Cancer. Ann Thorac Surg 2018;105:1476-82.

4. Yerokun BA, Sun Z, Yang CJ, et al. Minimally Invasive Versus Open Esophagectomy for Esophageal Cancer: A Population-Based Analysis. Ann Thorac Surg 2016;102:416-23.

5. Sundaram A, Srinivasan A, Baker S, et al. Readmission and risk factors for readmission following esophagectomy for esophageal cancer. J Gastrointest Surg 2015;19:581-5; discussion 586.

6. Hu Y, McMurry TL, Stukenborg GJ, et al. Readmission predicts 90-day mortality after esophagectomy: Analysis of Surveillance, Epidemiology, and End Results Registry linked to Medicare outcomes. J Thorac Cardiovasc Surg 2015;150:1254-60.

7. Stitzenberg KB, Chang Y, Smith AB, et al. Exploring the burden of inpatient readmissions after major cancer surgery. J Clin Oncol 2015;33:455-64.

8. Project HCaU. NRD Overview Rockville, MD: Agency for Healthcare Research and Quality; 2019 Available online: www.hcup-us.ahrq.gov/nrdoverview.jsp

9. Varghese TK Jr, Wood DE, Farjah F, et al. Variation in esophagectomy outcomes in hospitals meeting Leapfrog volume outcome standards. Ann Thorac Surg

Cite this article as: Wang Y, Yang CFJ, He H, Buchan JM, Patel DC, Liou DZ, Lui NS, Berry MF, Shrager JB, Backhus LM. Short-term and intermediate-term readmission after esophagectomy. J Thorac Dis 2021;13(8):4678-4689. doi: 10.21037/ jtd-21-637
2011;91:1003-9; discussion 1009-10.

10. Blencowe NS, Strong S, McNair AG, et al. Reporting of short-term clinical outcomes after esophagectomy: a systematic review. Ann Surg 2012;255:658-66.

11. Chen SY, Molena D, Stem M, et al. Post-discharge complications after esophagectomy account for high readmission rates. World J Gastroenterol 2016;22:5246-53.

12. Fernandez FG, Khullar O, Force SD, et al. Hospital readmission is associated with poor survival after esophagectomy for esophageal cancer. Ann Thorac Surg 2015;99:292-7.

13. Low DE, Kuppusamy MK, Alderson D, et al. Benchmarking Complications Associated with Esophagectomy. Ann Surg 2019;269:291-8.

14. Mitzman B, Lutfi W, Wang CH, et al. Minimally Invasive Esophagectomy Provides Equivalent Survival to Open Esophagectomy: An Analysis of the National Cancer Database. Semin Thorac Cardiovasc Surg 2017;29:244-53.

15. Schmidt HM, El Lakis MA, Markar SR, et al. Accelerated Recovery Within Standardized Recovery Pathways After Esophagectomy: A Prospective Cohort Study Assessing the Effects of Early Discharge on Outcomes, Readmissions, Patient Satisfaction, and Costs. Ann Thorac Surg 2016;102:931-9.

16. Shah SP, Xu T, Hooker CM, et al. Why are patients being readmitted after surgery for esophageal cancer? J Thorac Cardiovasc Surg 2015;149:1384-9; discussion 1389-91.

17. Zafar SN, Shah AA, Nembhard C, et al. Readmissions After Complex Cancer Surgery: Analysis of the Nationwide Readmissions Database. J Oncol Pract 2018;14:e335-45.

18. Modrall JG, Minter RM, Minhajuddin A, et al. The Surgeon Volume-outcome Relationship: Not Yet Ready for Policy. Ann Surg 2018;267:863-7. 


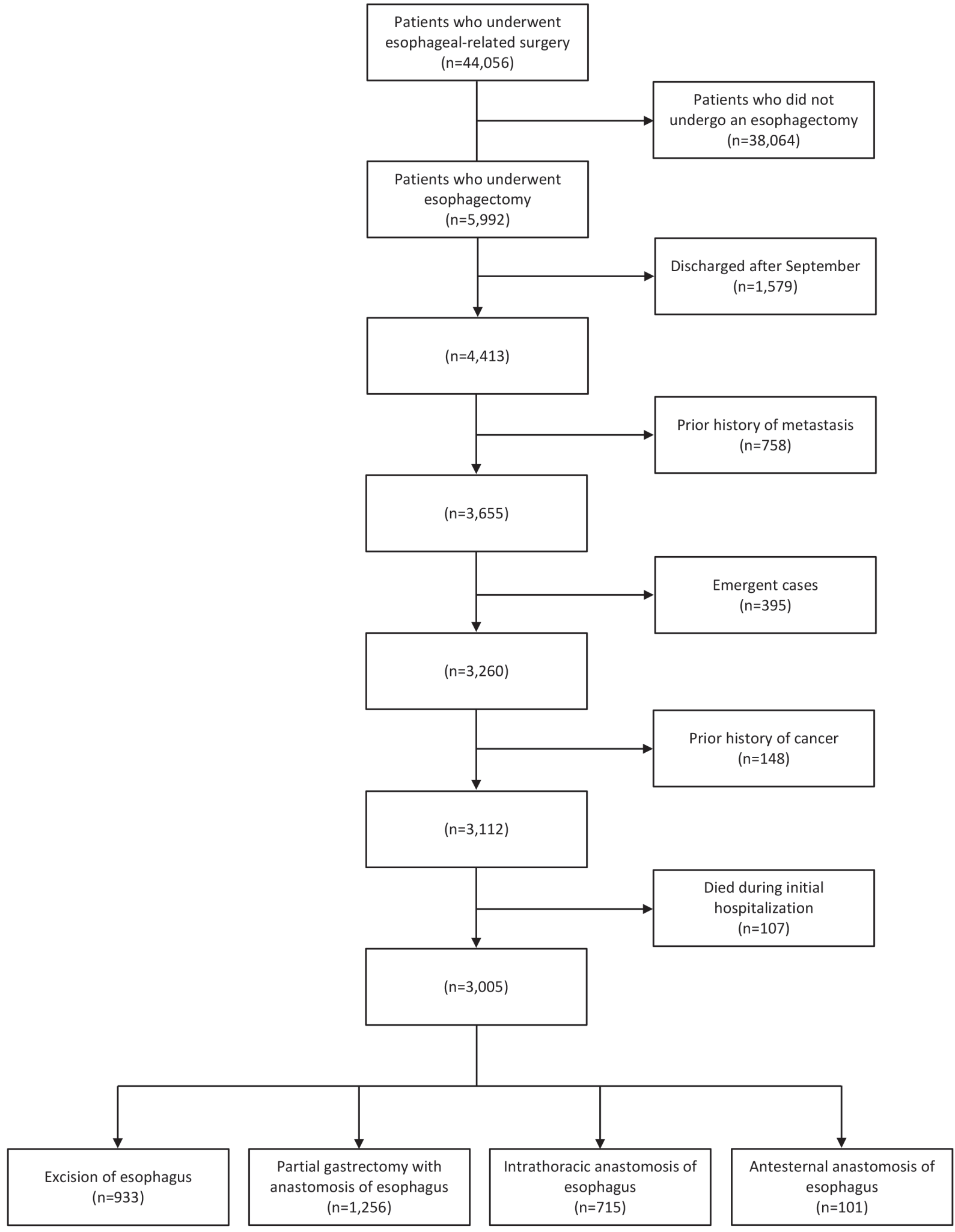

Figure S1 Flow diagram showing patient selection.

(c) Journal of Thoracic Disease. All rights reserved. 
Table S1 Anastomotic technique

\begin{tabular}{|c|c|c|c|}
\hline Anastomotic technique & $\begin{array}{l}\text { Readmission within 0-30 days } \\
\qquad(\mathrm{n}=171)\end{array}$ & $\begin{array}{l}\text { Readmission within 31-90 days } \\
\qquad(\mathrm{n}=91)\end{array}$ & $\begin{array}{l}\text { Not readmitted within } 90 \text { days } \\
\qquad(n=605)\end{array}$ \\
\hline Intrathoracic esophagoesophagostomy & $6(3.5 \%)$ & $7(7.7 \%)$ & $25(4.1 \%)$ \\
\hline Intrathoracic esophagoenterostomy & $28(16.4 \%)$ & $12(13.2 \%)$ & $85(14.0 \%)$ \\
\hline Intrathoracic esophagocolostomy & $5(2.9 \%)$ & $4(4.4 \%)$ & $12(2.0 \%)$ \\
\hline Antesternal esophagogastrostomy & $12(7.0 \%)$ & $6(6.6 \%)$ & $63(10.4 \%)$ \\
\hline Antesternal esophagoenterostomy & $1(0.6 \%)$ & 0 & $1(0.2 \%)$ \\
\hline Antesternal esophagocolostomy & $4(2.3 \%)$ & 0 & $7(1.2 \%)$ \\
\hline
\end{tabular}


Table S2 ICD-9 Diagnosis codes for postoperative infection following esophagectomy

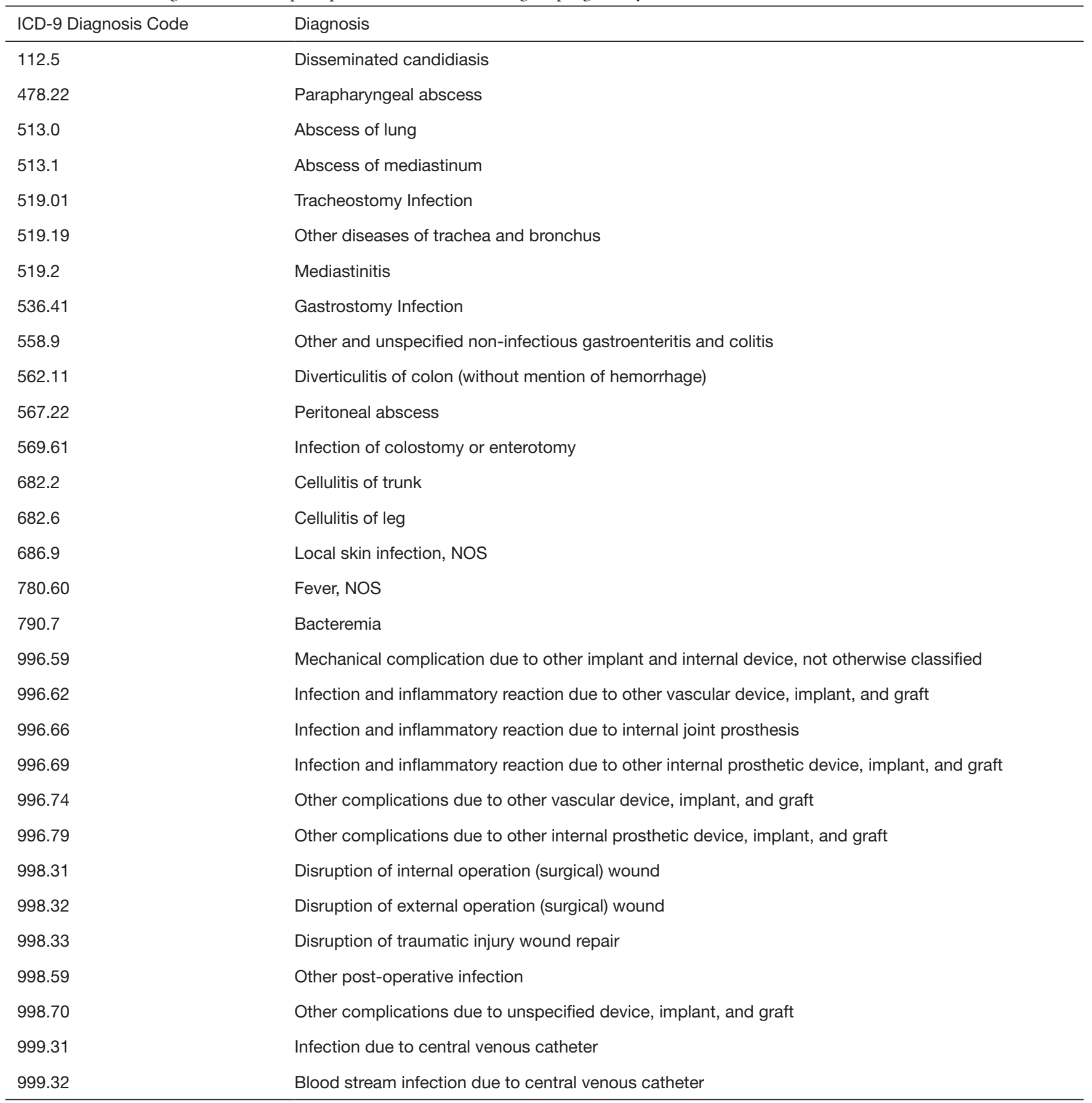

